\title{
EVALUATION OF OAT GRAIN PERTINENCE TO PRODUCTION OF FLAKES, FLOUR AND PORRIDGE PREPARING
}

\author{
Vita Sterna $^{1 *}$, LailaVilmane ${ }^{2}$, Sanita Zute ${ }^{2}$, Zaiga Vicupe ${ }^{2}$, Ineta Karkla ${ }^{3}$ \\ ${ }^{\prime}$ Department of agro-ecological research, Stende Research Centre, Institute of Agricultural Resources and Economics, "Dizzemes", \\ Dizstende, Libagi parish, Talsi County, Latvia, e-mail: vita.sterna@arei.lv \\ ${ }^{2}$ Department of Crop Breeding and Genetics, Stende Research Centre, Institute of Agricultural Resources and Economics \\ „Dizzemes”, Dizstende, Libagi parish, Talsi County, Latvia \\ ${ }^{3}$ JSC Dobeles dzirnavnieks, Spodribas street 4, Dobele, Latvia
}

\begin{abstract}
Oats for human consumption are primarily used as oat flakes and breakfast mixes. Although cultivar differences in the parameters directing oat breeding and cultivation such as seed size, yield, lodging resistance, and nutritional attributes - protein, lipids, are widely studied, knowledge concerning the suitability of cultivars for production of flakes and other oat products is limited The aim of present investigation was to study chemical composition - protein, fat $\beta$-glucans content of new oat genotypes and its pertinence to needs of producers - thousand grain weight, kernel outcome and colour of porridge.

The grain of twelve oat genotypes VP2, VP3, VP4, VP5, VP6, VP8, VP9, VP10, VP11, VP12 and two recognized varieties - 'Laima' and 'Peppi' were the materials used in study. In the studied samples content of protein, lipids, $\beta$-glucans same as grain outcome, damaged and dark grain were determined. Oat flakes were made and prepared porridge. Colour difference of oat porridges between genotypes was tested. The results showed that protein content in oat grain ranged from $10.2 \%$ to $14.7 \%$, lipids from $5.3 \%$ to $7.7 \%$ and $\beta$-glucans from 1.8 to $3.6 \%$ depending on genotype. More perspective breeding lines from nutritional point of view were VP4 and VP3, but from the higher outcome and grain quality perspective, VP8 and VP12. Colour analysis of porridge confirmed that all analysed oat genotypes fulfilled colour requirements and were in agreement with products, which are on the market.
\end{abstract}

Keywords: hulled oats, nutrition value, production, quality, outcome.

\section{Introduction}

Grains, including oats (Avena sativa L.), have been recognized as a healthy food containing significant amounts of soluble dietetic fibre, $\beta$-glucans, polyunsaturated fatty acids and vitamin $\mathrm{E}$ because provide beneficial effect on the health of the consumer and decrease the risk of various diseases (Lásztity, 1998; Sterna et al., 2014; Zielinski et al., 2001). The incorporation of oat grains and oat bran in the food products improves not only the nutrition but also a therapy against various maladies (Butt et al., 2008).

The discussion on oat grain dietetic value and suitability to the production of functional foods is more frequently mentioned in scientific literature by Biel et al. (2009). Food uses for oats include oat flour, oat bran, oat flakes, which mainly used for porridge and breakfast cereals. Oat flour is also used as a thickener in many infant foods (Arendt, Zannini, 2013).

It is possible to produce oats with specific health benefits and genotype traits, therefore it is necessary to compare the chemical composition and quality traits of new breeding lines grains with producers recognized varieties. Although cultivar differences in the parameters directing oat breeding and cultivation such as seed size, yield, lodging resistance, and nutritional attributes such as protein, oil, and $\beta$-glucans are widely studied, knowledge concerning the suitability of cultivars for rolled oats production is limited (Lapveteläinen et al., 2001). Critical manufacturing criteria such as degree of dehulling, kernel outcome and amount of dark grain could be desirable determined in the evaluation of grains.

The aim of present investigation was to study chemical composition - protein, fat $\beta$-glucans content of new oat genotypes and its pertinence to needs of producers - thousand grain weight, kernel outcome and colour of porridge.

\section{Materials and Methods}

The research was conducted at the Institute of Agricultural Resources and Economics, Stende Research Centre from 2015 to 2016.

The characteristic of environmental conditions in 2015 and 2016 years showed in the Table 1.

Table 1

The characteristic of environmental conditions in years 2015 and 2016

\begin{tabular}{|c|c|c|c|c|}
\hline \multirow{2}{*}{ Month } & \multicolumn{2}{|c|}{ Temperature } & \multicolumn{2}{|c|}{ Precipitation } \\
\hline & 2015 & 2016 & 2015 & 2016 \\
\hline April & 5.6 & 5.8 & 98.5 & 37.0 \\
\hline May & 9.8 & 13.3 & 65.9 & 61.0 \\
\hline June & 13.5 & 15.6 & 50.5 & 92.5 \\
\hline July & 15.9 & 17.2 & 75.5 & 91.7 \\
\hline August & 17.5 & 16.0 & 26.6 & 110.4 \\
\hline & \multicolumn{2}{|c|}{ Soil traits } & 2015 & 2016 \\
\hline \multicolumn{3}{|l|}{$\mathrm{pH}$} & 5.6 & 5.6 \\
\hline \multicolumn{3}{|c|}{ Organic matter, \% } & 2.6 & 1.7 \\
\hline \multicolumn{3}{|c|}{$\mathrm{P}_{2} \mathrm{O}_{5}, \mathrm{mg} \mathrm{kg}^{-1}$} & 180 & 174 \\
\hline \multicolumn{3}{|c|}{$\mathrm{K}_{2} \mathrm{O}, \mathrm{mg} \mathrm{kg}^{-1}$} & 117 & 162 \\
\hline
\end{tabular}

Twelve oat genotypes VP2, VP3, VP4, VP5, VP6, VP8, VP9, VP10, VP11, VP12 and two millers recognized varieties - 'Laima' as a widely grown variety in Latvia, and 'Peppi' from Finland as a preferred among imported grains, were the materials used in this study.

Mean samples from all (4) replicates $(0.5 \mathrm{~kg})$ were taken for laboratory testing. Hulled grains were dehulled mechanically. In the studied samples $(n=96)$ test weight, 1.000 grain weight (TGW), protein, lipid and $\beta$-glucans 
content were determined by using automatic grain analyser Infratec Analyser 1241.

Critical manufacturing criteria such as degree of dehulling (grain outcome), kernel outcome and amount of dark grain were determined.

Oat flakes were made from whole oats grain, which were rolled info flat flakes under heavy rollers using laboratory equipment MARGA Mulino (Marcato, Italy). Porridge was prepared by mixing $20 \mathrm{~g}$ of oat flakes with $50 \mathrm{~mL}$ boiling water and left to swell for $15 \mathrm{~min}$.

The instrumental measurement of porridge colour was performed in CIE (International Commission on Illumination) L*a*b* using a ColorTec-PCM/PSM (Accuracy Microsensors Inc., USA). In colour measurement, CIE $L^{*} a^{*} b^{*}$ coordinates show the degree of brightness (L), the degree of redness $(+a)$, or greenness $(-\mathrm{a})$, and the degree of yellowness $(+b)$, or blueness (-b), respectively (Phimolsiripol et al., 2012). Porridge colour measurements were made by placing the samples directly under the colorimeter. The colour was measured at five different points within the porridge region and mean values were reported for each porridge. The total colour difference $(\Delta \mathrm{E})$ was defined by the Minolta equations (1) (Sanz et al., 2009):

$$
\begin{aligned}
\Delta L & =\left(L-L_{0}\right), \Delta a=\left(a-a_{0}\right), \Delta b=\left(b-b_{0}\right), \\
\Delta E & =\sqrt{\Delta L^{2}+\Delta a^{2}+\Delta b^{2}},
\end{aligned}
$$

where $\mathrm{L}, \mathrm{a}$, and $\mathrm{b}$ are the measured values of oat genotypes porridge samples, $\mathrm{L}_{0}, \mathrm{a}_{0}$, and $\mathrm{b}_{0}$ are the values of oat variety 'Laima' and 'Peppi' porridge (control), which were selected as reference values.

The reference values for calculating $\Delta \mathrm{E}$ then were the colour difference between control and each porridge sample. The values used to determine whether the total colour difference is appreciable by the human eye were the following:

○ $\Delta \mathrm{E}<1-$ colour difference is not obvious for the human eye;

○ $1<\Delta \mathrm{E}<3$ - colour difference is not appreciative by the human eye;

- $\Delta \mathrm{E}>3-$ colour difference is obvious for the human eye (Sanz et al., 2009).

The results were statistically processed using methods of descriptive statistics, analysis of variance, using programme package SPSS 20. Statistical significance was declared at $\mathrm{p}<0.05$ or at $\mathrm{p}<0.01$.

\section{Results and Discussion}

The results of analysed protein, lipid, $\beta$-glucans content and thousand grain weight in the hulled oat varieties and breeding lines grain are summarized in Table 2.

The results of investigation showed that the content of protein in samples of oat grains depended on genotype and ranged from $10.7 \%$ to $13.9 \%$. The significantly highest protein content $-13.9 \pm 1.2 \%$ determined in the samples of oat variety 'Peppi' $(p<0.05)$. From tested new genotypes highest protein content determined in the samples of VP4 $11.8 \pm 0.6 \%$. Our results are similar with other research findings, where protein content for husked oat was reported to be $11.5 \%$ (Biel et al., 2009) and $15.9 \%$ (Asp et al., 1992).

Table 2

Content of protein, fat, $\beta$-glucans and thousand grain weight in different genotypes grain

\begin{tabular}{ccccc}
\hline \multirow{2}{*}{ Samples } & Protein & Fat & $\boldsymbol{\beta}$-glucans & TGW \\
\cline { 2 - 5 } & $\boldsymbol{\%}$ & $\boldsymbol{\%}$ & $\boldsymbol{\%}$ & $\mathbf{g}$ \\
\hline 'Laima' & $11.8 \pm 0.4$ & $7.7 \pm 0.3$ & $3.3 \pm 0.3$ & $35.6 \pm 1.8$ \\
VP2 & $11.7 \pm 0.4$ & $6.4 \pm 0.2$ & $2.5 \pm 0.2$ & $36.4 \pm 2.6$ \\
VP3 & $11.4 \pm 0.4$ & $6.8 \pm 0.1$ & $2.6 \pm 0.1$ & $38.5 \pm 4.2$ \\
VP4 & $11.8 \pm 0.6$ & $6.6 \pm 0.3$ & $2.7 \pm 0.2$ & $39.4 \pm 3.6$ \\
VP5 & $11.6 \pm 0.5$ & $6.6 \pm 0.1$ & $2.6 \pm 0.1$ & $38.6 \pm 4.9$ \\
VP6 & $11.3 \pm 0.4$ & $6.5 \pm 0.2$ & $2.4 \pm 0.2$ & $39.6 \pm 2.8$ \\
'Peppi' & $13.9 \pm 1.2$ & $6.7 \pm 0.2$ & $3.0 \pm 0.1$ & $38.4 \pm 1.5$ \\
VP8 & $10.7 \pm 0.6$ & $5.7 \pm 0.1$ & $2.0 \pm 0.1$ & $37.3 \pm 3.8$ \\
VP9 & $11.3 \pm 0.6$ & $6.3 \pm 0.3$ & $2.5 \pm 0.1$ & $40.5 \pm 2.8$ \\
VP10 & $11.1 \pm 0.7$ & $6.4 \pm 0.3$ & $2.4 \pm 0.1$ & $36.5 \pm 4.7$ \\
VP11 & $10.7 \pm 0.4$ & $6.7 \pm 0.1$ & $2.6 \pm 0.1$ & $41.7 \pm 0.8$ \\
VP12 & $11.2 \pm 0.6$ & $6.5 \pm 0.3$ & $2.5 \pm 0.1$ & $35.1 \pm 3.3$ \\
\hline
\end{tabular}

The fat content ranged from $5.7 \pm 0.1 \%$ in the grains of genotype VP8 to $7.7 \pm 0.3 \%$ in the grains of variety 'Laima'. From tested new genotypes highest fat content determined in samples of VP3 $(6.8 \pm 0.1)$. The fat content of oat grains depends on genetic and environmental factors. The range of 3.1 to $11.6 \%$ was found among more than 4000 entries in the world collection (Zhou et al., 1999).

Content of $\beta$-glucans besides health benefits has also high impact on the oat flakes production quality (Lapveteläinen et al., 2001). The content of $\beta$-glucans in hulled oat grains varied from $2.0 \%$ to $3.3 \%$. The varieties 'Laima', 'Peppi' and genotypes VP4 and VP3 had on average $3.3 \%, 3.0 \%, 2.7 \%$ and $2.6 \%$-glucans content, respectively. The content of $\beta$-glucans significantly differed among genotypes $(\mathrm{p}<0.05)$, and it is in agreement with other scientific investigations (Welch, 1995, Lapveteläinen et al., 2001, Arendt, Zannini, 2013).

Data of investigation must be concluded that the better new breeding lines from nutritional point of view were VP4 with highest protein and $\beta$-glucans content and VP3 with highest fat and $\beta$-glucans content (Table 2). Comparison of oats grain yield and quality criteria such as grain outcome, kernel outcome, amount of dark and damaged grain content are showed in Table 3.

Data of investigation showed (Table 3 ) that genotypes with higher protein content - 'Peppi', 'Laima' and VP4 had lower grain yield 4.83, 5.73, and $5.74 \mathrm{tha}^{-1}$ respectively. The high protein content in grains often accompanied by low yield. A tendency toward a negative relationship between protein concentration and yield is generally expected (Burrows, 1986), although various genotypes may respond differently (Givens et al., 2004).

Investigation of grain quality showed that the smallest content of damaged grain was for oat variety 'Laima', the smallest content of dark grain has samples of breeding line VP3, VP4, and VP8 (Table 3). 
Grain yield, outcome and quality traits in different oat genotypes

\begin{tabular}{lccccc}
\hline \multirow{2}{*}{ Genotypes } & Yield, t ha $\mathbf{~}^{\mathbf{1}}$ & Grain outcome, \% & \multicolumn{3}{c}{ Kernel outcome*, \% } \\
\cline { 3 - 6 } & & above 2 mm sieve & Damaged grain* & Dark grain & Clean \\
\hline 'Laima & $5.73 \pm 0.43$ & $99.0 \pm 0.1$ & $3.74 \pm 0.34$ & $1.85 \pm 0.14$ & $68.6 \pm 0.2$ \\
VP2 & $6.00 \pm 0.42$ & $99.4 \pm 0.1$ & $7.41 \pm 0.55$ & $2.47 \pm 0.18$ & $73.4 \pm 0.5$ \\
VP3 & $6.43 \pm 0.21$ & $99.3 \pm 0.2$ & $7.06 \pm 0.54$ & $0.94 \pm 0.12$ & $66.7 \pm 0.2$ \\
VP4 & $5.74 \pm 0.41$ & $99.5 \pm 0.2$ & $8.20 \pm 0.34$ & $1.62 \pm 0.14$ & $78.9 \pm 0.5$ \\
VP5 & $6.16 \pm 0.45$ & $99.4 \pm 0.1$ & $12.65 \pm 0.58$ & $2.18 \pm 0.14$ & $66.3 \pm 0.2$ \\
VP6 & $6.25 \pm 0.42$ & $99.3 \pm 0.3$ & $7.32 \pm 0.54$ & $3.84 \pm 0.25$ & $65.3 \pm 0.2$ \\
'Peppi' & $4.83 \pm 0.65$ & $99.0 \pm 0.4$ & $5.92 \pm 0.56$ & $4.19 \pm 0.34$ & $75.8 \pm 0.5$ \\
VP8 & $6.36 \pm 0.50$ & $99.6 \pm 0.2$ & $5.40 \pm 0.34$ & $1.78 \pm 0.14$ & $67.1 \pm 0.3$ \\
VP9 & $6.60 \pm 0.48$ & $99.0 \pm 0.3$ & $8.97 \pm 0.64$ & $1.82 \pm 0.14$ & $68.0 \pm 0.4$ \\
VP10 & $6.53 \pm 0.32$ & $99.1 \pm 0.1$ & $10.18 \pm 0.65$ & $3.20 \pm 0.35$ & $66.2 \pm 0.3$ \\
VP11 & $6.00 \pm 0.58$ & $99.8 \pm 0.2$ & $5.00 \pm 0.34$ & $2.38 \pm 0.14$ & $66.8 \pm 0.4$ \\
VP12 & $6.80 \pm 0.42$ & $98.0 \pm 0.1$ & $8.45 \pm 0.64$ & $2.03 \pm 0.18$ & $76.6 \pm 0.5$ \\
\hline
\end{tabular}

* - average values and standard deviations

The highest outcome of clean kernel observed in samples of variety 'Peppi' and breeding lines VP12 and V4. The results of damaged and dark grain content significantly differed by breeding lines $(\mathrm{p}<0.05)$. A three-year study made by Lapveteläinen et al. (2001) showed that both cultivar and crop year significantly influenced yield, TGW, kernel size value, damaged and dark grain amount, and damaged flake particles. Evaluation of grain yield, grain outcome and most important traits from producer's point of view showed that better quality often combined with lower yield.

Evaluation of new breeding lines technological characteristic were included quality of flakes and colour values of porridge. Oat grains after being rolled info flat flakes, control and analysed sample average flake size are 11-13 mm (Fig. 1). Oat flakes characterise oval and elongated shape, and they are fragile.

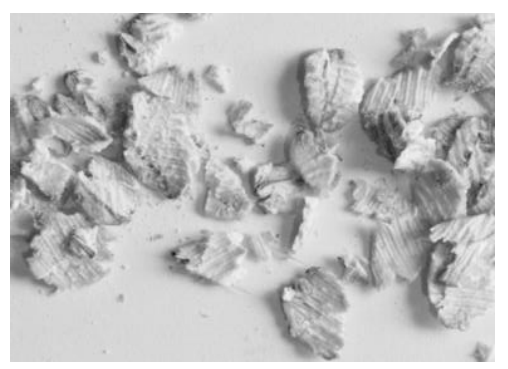

Figure 1. Oat flakes after rolling

After oat flakes are mixed with boiling water, flakes begin to lose shape, divided into smaller pieces; starch granules swell and give porridge homogeneous structure.

Colour is variable measurement, depends on used materials, temperature, storage conditions and time, and spot of the measurement (Mondal, Datta, 2008). Colour values of oat porridge are shown in Table 4.

No significant differences were found in $\mathrm{L}^{*}$ and $\mathrm{b}^{*}$ values of oat porridge between each type of genotype and variety. Oat porridge had grey, dark grey colour. Significant differences $(\mathrm{p}<0.05)$ were found in $\mathrm{a}^{*}$ values, it range from $-0.23 \pm 0.87$ genotype VP9 to $-2.56 \pm 0.52$ genotype VP3.
Colour values of oat porridge

\begin{tabular}{lccc}
\hline \multirow{2}{*}{ Samples } & \multicolumn{3}{c}{ Colour } \\
\cline { 2 - 4 } & $\mathbf{L}^{*}$ & $\mathbf{a}^{*}$ & $\mathbf{b}^{*}$ \\
\hline 'Laima' & $89.81 \pm 0.76^{*}$ & $-2.39 \pm 0.88$ & $21.04 \pm 0.71$ \\
VP2 & $87.88 \pm 0.87$ & $-1.86 \pm 0.55$ & $23.13 \pm 0.83$ \\
VP3 & $87.61 \pm 0.69$ & $-2.56 \pm 0.52$ & $21.48 \pm 0.56$ \\
VP4 & $89.90 \pm 0.59$ & $-1.53 \pm 0.72$ & $21.71 \pm 0.49$ \\
VP5 & $88.06 \pm 0.13$ & $-1.78 \pm 0.41$ & $23.97 \pm 0.61$ \\
VP6 & $88.39 \pm 0.28$ & $-0.82 \pm 0.54$ & $22.94 \pm 0.69$ \\
'Peppi' & $89.94 \pm 0.46$ & $-2.02 \pm 0.33$ & $22.42 \pm 0.49$ \\
VP8 & $87.86 \pm 0.40$ & $-0.58 \pm 0.11$ & $22.20 \pm 0.37$ \\
VP9 & $88.36 \pm 0.85$ & $-0.23 \pm 0.87$ & $22.01 \pm 0.84$ \\
VP10 & $88.44 \pm 0.40$ & $-0.46 \pm 0.25$ & $23.77 \pm 0.75$ \\
VP11 & $88.34 \pm 0.42$ & $-1.69 \pm 0.60$ & $23.82 \pm 0.72$ \\
VP12 & $89.92 \pm 0.25$ & $-1.95 \pm 0.52$ & $22.78 \pm 0.48$ \\
\hline * average values and standard deviations
\end{tabular}

In order to study if there are colour differences between varieties 'Laima' and 'Peppi', and each oat genotype were detectable by human eye, the parameter $\Delta \mathrm{E}$ was calculated (Table 5).

Parameter $\Delta \mathrm{E}$ revealed that the colour difference between porridge of variety 'Laima' and porridge of genotypes VP5, VP10 and VP11 was obvious for human eye $(\Delta E>3)$.

Porridge of genotypes are darker than from variety 'Laima'. Colour difference of oat porridge between variety 'Laima' and other genotypes are not appreciative by the human eye $(1<\Delta \mathrm{E}<3)$.

Table 5

Colour difference $(\Delta E)$ of oat porridge

\begin{tabular}{lcc}
\hline \multirow{2}{*}{ Genotype } & \multicolumn{2}{c}{ Variety } \\
\cline { 2 - 3 } & 'Laima' & 'Peppi' \\
\hline VP2 & 2.89 & 2.18 \\
VP3 & 2.25 & 2.57 \\
VP4 & 1.09 & 0.86 \\
VP5 & 3.47 & 2.45 \\
VP6 & 2.84 & 2.03 \\
VP8 & 2.90 & 2.54 \\
VP9 & 2.78 & 2.42 \\
VP10 & 3.61 & 2.55 \\
VP11 & 2.15 \\
VP12 & 3.22 & 0.37 \\
\hline
\end{tabular}


Colour difference of oat porridge between variety 'Peppi' and genotypes VP4 and VP12 was not obvious for the human eye $(\Delta \mathrm{E}<1)$, but comparing with other analysed genotypes difference were not appreciative by the human eye $(1<\Delta \mathrm{E}<3)$.

'Laima' and 'Peppi' are most common oat varieties, which are used in oat flake production in Latvia, colour analysis of porridge reveals that each of analysed oat genotype can be equal in colour with products, which are on the market.

\section{Conclusions}

The content of protein, fat, $\beta$-glucans, same as a quality of traits significantly differed by genotypes. More perspective breeding lines from nutritional point of view are VP4 and VP3, from the higher outcome and grain quality perspective VP8. Evaluation of grain yield, grain outcome and most important traits from producer's point of view showed that better quality is often combined with lower yield. Colour analysis of porridge reveals that each of analysed oat genotype can be equal in colour with products, which are on the market.

\section{Acknowledgment}

This research was supported by National Research Programme AgroBioRes project "Sustainable use of local agricultural resources for qualitative and healthy food product development" (FOOD) No 10-4/VPP-7/3.

\section{References}

1. Arendt E.K., Zannini E. (2013) Oats. In: Cereal grains for the food and beverage industries. S. Hughes, R. Cox (eds). Woodhead Publishing Limited. p. 243-282.

2. Asp N.G., Mattsson B., Onning G. (1992) Variation in dietary fibre, $\beta$-glucan, starch, protein, fat and hull content of oats grown in Sweden 1987-1989. European Journal of Clinical Nutrition, Vol. 46, p. 31-37.

3. Biel W., Bobko, K., Maciorowski R. (2009) Chemical composition and nutritive value of husked and naked oats grain. Journal of Cereal Science, Vol. 49, p. 413-418.
4. Burrows V. D. (1986) Breeding oats for food and feed: Conventional and new techniques and materials. In: Oats: Chemistry and Technology. F. W. Webster, ed. Am. Assoc. Cereal Chem.: St. Paul, MN. p. 13.

5. Butt M.S., Tahir-Nadeem M., Khan M. K. I., Shabir R., Butt M.S. (2008) Oat: unique among the cereals. European Journal of Nutrition, Vol. 47, p. 68-79.

6. Givens D.I., Davies T.W., Laverick R.M. (2004) Effect of variety, nitrogen fertilizer and various agronomic factors on the nutritional value of husked and naked oats grain. Animal Feed Science and Technology, Vol. 113, p. 169-181.

7. Lapveteläinen A., Alho-Lehto P., Sinn L., Laukkanen T., Lindman T., Kallio H., Kaitaranta J., Katajisto J. (2001) Relationships of selected physical, chemical, and sensory parameters in oat grain, rolled oats, and cooked oatmeal A three-year study with eight cultivars. Cereal Chemistry, Vol. 78(3), p. 322-329.

8. Lásztity R. (1998) Oat grain - a wonderful reservoir of natural nutrients and biologically active substances, Food Reviews International, Vol. 14(1), p. 99-119.

9. Mondal A, Datta A. K. (2008) Bread baking - A review, Journal of Food Engineering, Vol. 86, p. 465-474.

10. Phimolsiripol Y., Mukprasirt A., Schoenlechner R. (2012) Quality improvement of rice-based gluten-free bread using different dietary fibre fractions of rice bran. Journal of Cereal Science, Vol. 56, p. 389-395.

11. Sanz T., Salvador A., Baixauli R., Fiszman S.M. (2009) Evaluation of flour of resistant starch in muffins. II. Effects in texture, colour and consumer response. European Food Research and Technology, Vol. 229, p. 197-204.

12. Sterna V., Zute, S., Brunava, L., Vicupe Z. (2014) Lipid composition of oat grain grown in Latvia. In: 9th Baltic Conference on Food science and Technology "Food for Consumer Well-being" FOODBALT 2014. Conference proceedings, Latvia, Jelgava p. 72-76.

13. Welch R. W. (1995) The Oat Crop: Production and Utilization, London, Chapman \& Hall, 516 S.

14. Zielinski, H., Ciska, E., Kozlowska, H. (2001) The cereal grains: Focus on vitamin E, Czech Journal of Food Science, Vol. 19, p. 182-188.

15. Zhou M.X., Robards K., Glennie-Holmes M., Helliwell S. (1999) Oat Lipids, Journal of American Oil Chemistry Science, Vol. 79, p.585-592. 